\title{
TNF- $\alpha$ gene polymorphism and plasma TNF- $\alpha$ levels are related to lumbar spine bone area in healthy female Caucasian adolescents
}

\author{
P Wennberg ${ }^{1}$, P Nordström ${ }^{1,2}$, R Lorentzon ${ }^{1,4}, \mathrm{U}^{\mathrm{H}}$ Lerner $^{3}$ and M Lorentzon ${ }^{1}$ \\ ${ }^{1}$ Sports Medicine, Department of Surgical and Perioperative Sciences, ${ }^{2}$ Department of Geriatric Medicine, ${ }^{3}$ Department of Odontology, Oral Cell Biology, \\ Umeå University, 90185 Umeå and ${ }^{4}$ Centre for Musculoskeletal Research, National Institute of Working Life, Umeå, Sweden \\ (Correspondence should be addressed to M Lorentzon; Email: Mattias.Lorentzon@idrott.umu.se)
}

\begin{abstract}
Objective: The cytokine tumor necrosis factor alpha (TNF- $\alpha$ ) is an important regulator of bone metabolism. Polymorphisms in the promoter region of the TNF- $\alpha$ gene at positions -308 and -863 have been identified. We investigated whether these polymorphisms and circulating TNF- $\alpha$ levels were related to bone mineral density and bone area in adolescent girls.

Design: Bone mineral density (BMD), bone area (BA), anthropometric characteristics and biochemical analyses were measured in adolescent girls and compared with regard to TNF- $\alpha$ genotype.

Methods: Allelic variants of the TNF- $\alpha$ gene in 97 girls, aged 16.9 \pm 1.2 years (mean \pm S.D.), were identified using polymerase chain reaction and the restriction endonucleases NcoI and TaiI. Bone mineral density and bone area of the femoral neck, lumbar spine and total body were measured using dual energy X-ray absorptiometry.

Results: Carriers of the rare $-863 \mathrm{~A}$ allele $(n=25)$ had higher body weight $(P=0.03)$, lumbar spine BMD $(P=0.02)$, and larger total BA $(P=0.03)$, femoral neck area $(P<0.05)$, and lumbar spine area $(P=0.01)$. The independent predictors of BMD and BA were investigated using multiple regression. The TNF- $\alpha-863$ genotypes $(\beta=0.18, P=0.03)$ and the TNF- $\alpha$ plasma levels $(\beta=$ $0.19, P=0.04)$ independently predicted BA of the lumbar spine but not BA or BMD of any other measured sites. No statistically significant differences in body constitution parameters, biochemical parameters, bone density, or bone area at the measured skeletal sites were found when comparing the groups defined by the allelic variants at position $-308(P=0.17-0.84)$.

Conclusions: We found the TNF- $\alpha-863$ polymorphism and the TNF- $\alpha$ plasma levels to be independent predictors of lumbar spine area in healthy Caucasian adolescent females.
\end{abstract}

European Journal of Endocrinology 146 629-634

\section{Introduction}

The incidence of osteoporosis is rapidly increasing in most Western societies and the disease affects up to $40 \%$ of women and $12 \%$ of men at some point during life (1). A common result of the disease is hip fracture, which has doubled in incidence in both sexes since the 1950 s (2) and is expected to rise another twofold by the year 2025 (3).

Bone mineral density (BMD) is strongly genetically determined. Twin and family studies have shown that up to $80 \%$ of the age-specific variation in BMD is under genetic influence $(4,5)$. The maximal attained bone mass in life, peak bone mass, accounts for about half of the BMD variation up to 65 years of age (6). Since BMD is a major determinant of future fracture risk (7), finding genetic markers for low peak bone mass in children and adolescents could lead to improved screening, diagnosis and early preventive measures, such as physical activity regimes and dietary optimization. It is not only mineral density of the skeleton that is important for bone strength. Bone size is a significant determinant for fractures of the vertebral bodies, as Gilsanz et al. (8) have shown. Even small changes in size, particularly in external diameter, have a major effect on mechanical properties of a bone (9).

The multifunctional cytokine, tumor necrosis factor- $\alpha$ (TNF- $\alpha$ ), has been shown to stimulate bone resorption in vitro (10) and in mice (11). The cytokine has been implicated in diseases with increased osteoclastic bone resorption, such as osteoporosis due to loss of gonadal function (12), rheumatoid arthritis (13), periodontitis (14), and loosening of orthopaedic implants (15). Direct evidence of a stimulatory effect by TNF- $\alpha$ on osteoclast formation has been obtained in both 
human (16) and mouse (17) bone marrow cultures. In a study by Ota et al. (18), linkage was found of a microsatellite near the TNF- $\alpha$ gene with osteoporosis in 192 Japanese sib-pairs.

Functional polymorphisms at position -308 and -863 in the promoter region of the human TNF- $\alpha$ gene (19) have been reported to be associated with altered TNF- $\alpha$ promoter activity $(20,21)$ and with different plasma levels of TNF- $\alpha$ in healthy men (21), which may have clinical importance in autoimmune and infectious diseases (22). To our knowledge, these polymorphisms and circulating TNF- $\alpha$ levels have never before been studied in relation to $\mathrm{BMD}$ or bone area (BA).

In the present study, we investigated whether these polymorphisms and circulating TNF- $\alpha$ levels were associated with bone density or bone area in healthy Caucasian 17-year-old females, i.e. when all subjects had attained their approximate peak bone mass (23, 24).

\section{Materials and methods}

\section{Subjects}

From advertisements and information in schools and

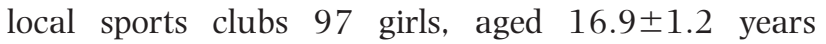
(mean \pm s.D.), all healthy Caucasians, volunteered to participate in the study. None of the subjects had any disease or medication known to affect bone metabolism. All girls had passed menarche by at least two years. Weight and height were measured using standardized equipment. Using a questionnaire, the average amount of weight bearing physical activity per week was assessed during the last year. Informed written consent was given by all the participants and the study protocol was approved by the Ethical Committee of the Medical Faculty, Umeå University.

\section{Techniques for estimating bone density}

BMD $\left(\mathrm{g} / \mathrm{cm}^{2}\right)$ and BA $\left(\mathrm{cm}^{2}\right)$ of the total body, femoral neck, and lumbar spine were measured using a Lunar DPX-L (Lunar Co, Madison, Wisconsin, USA) dual energy X-ray absorptiometer, software version $1.3 \mathrm{y}$. The precision of this method has previously been discussed in detail by others (25). The CV-value (s.D./mean) for repeated measurements is $0.7-2.0 \%$ in our laboratory depending on application.

\section{Biochemical analysis}

Blood samples were collected after an overnight fast. Osteocalcin was analyzed in plasma samples from 92 girls by a commercially available radioimmunoassay kit (Dia Sorin, Stillwater, MI, USA). All samples were analyzed in duplicate. The sensitivity of this assay was $0.8 \mathrm{ng} / \mathrm{ml}$. Intact parathyroid hormone (PTH) was measured in all 97 girls, using an Imulite intact PTH, solid-phase sandwich chemiluminescent immunological assay (DPC, CA, USA). Calcium was measured in plasma samples from 94 of the subjects using atomic absorption spectroscopy (26) with $1.2 \%$ intraassay precision. The Double Antibody Estradiol procedure (Diagnostic Products Corp., Los Angeles, CA, USA) was used to determine the levels of estradiol in whole blood. The method uses an anti-estradiol antiserum raised in rabbit. The radioactive ligand was ${ }^{125}$ I-labeled estradiol. Two samples from each subject were analyzed and the mean from these samples was then used in further analysis. The samples were analyzed according to the manufacturer's manual, the within-assay coefficient of variation $(\mathrm{CV})$ was $5 \%$ and the between-assay $\mathrm{CV}$ was $5.5 \%$. The sensitivity of the estradiol assay was $1.4 \mathrm{pg} / \mathrm{ml}$, according to the manufacturer of the assay. Plasma TNF- $\alpha$ levels were measured in 84 girls using the Quanikine HS kit (R\&D systems, Minneapolis, MN, USA). The sensitivity of this assay was $0.18 \mathrm{pg} / \mathrm{ml}$, according to the manufacturer.

\section{Genomic DNA analysis}

Genomic DNA from the participants was isolated from EDTA stabilized blood using the Wizard Genomic DNA Purification kit (Promega, Madison, WI, USA). Determination of the TNF- $\alpha$ gene polymorphisms at positions -308 and -863 was carried out as previously described $(19,21)$ with a few modifications. Amplification of the polymorphic sequence was performed with approximately $30 \mathrm{ng}$ genomic DNA, $0.2 \mathrm{mmol} / \mathrm{l}$ each of dATP, dCTP, dGTP, dTTP, $1 \times$ PCR buffer and $2.5 \mathrm{U}$ Taq polymerase in a $50 \mu \mathrm{l}$ reaction mixture (Roche Molecular Biochemicals, Stockholm, Sweden) with $0.4 \mu \mathrm{mol} / \mathrm{l}$ forward primer 5'-AGGCAATAGGTTTTGAGGGCCAT- $3^{\prime}$ and $0.4 \mu \mathrm{mol} / \mathrm{l}$ reverse primer $5^{\prime}$-TCCTCCCTGCTCCGATTCCG-3' for the TNF- $\alpha$ polymorphism at -308 and with $0.4 \mu \mathrm{mol} / \mathrm{l}$ forward primer 5'-GGCTCTGAGGAATGGGTTAC-3' and 0.4 $\mu \mathrm{mol} / \mathrm{l}$ reverse primer $5^{\prime}$-CTACATGGCCCTGTCTTCGTTACG-3' for the TNF- $\alpha$ polymorphism at -863 . For the TNF- $\alpha$ polymorphism at -308 , a total of 35 cycles of $30 \mathrm{~s}$ denaturation at $94^{\circ} \mathrm{C}, 30 \mathrm{~s}$ annealing at $60^{\circ} \mathrm{C}$, and $30 \mathrm{~s}$ elongation at $72^{\circ} \mathrm{C}$ (Peltier Thermocycler, MJ Research, Watertown, MA, USA) were used. For the TNF- $\alpha$ polymorphism at -863 , a total of 35 cycles of $30 \mathrm{~s}$ denaturation at $94^{\circ} \mathrm{C}, 1 \mathrm{~min}$ annealing at $59{ }^{\circ} \mathrm{C}$, and $1 \mathrm{~min}$ elongation at $72^{\circ} \mathrm{C}$ were used. The $-308 \mathrm{G}$ allele creates a cut site for the restriction endonuclease $\mathrm{NcoI}$ and the $-863 \mathrm{~A}$ allele creates a cut site for the restriction endonuclease Tail, while the $-308 \mathrm{~A}$ and $-863 \mathrm{C}$ alleles are left uncut. Ten microliters of the amplified products were cleaved overnight with the restriction endonuclease NcoI (New England Biolabs, Stockholm, Sweden) for TNF- $\alpha-308$ and the restriction endonuclease Tail (New England 
Biolabs) for TNF- $\alpha-863$, and electrophoresed and analyzed on ethidium bromide-stained agarose gel.

\section{Statistical analysis}

Differences in physical characteristics and bone density between the two groups defined by the TNF- $\alpha$ genotypes were investigated using an independent samples $t$-test, with Bonferroni's correction for multiple comparisons as post hoc test if a variable was found significant. Bivariate correlations of the different parameters (such as e.g. weight, height, and physical activity) related to BMD or BA were tested using Pearson's coefficient of correlation. The independent predictors of bone density and bone area were tested using multiple linear regression. The SPSS statistical package for the $\mathrm{PC}$ was used in the statistical analyses. A P-value less then 0.05 was considered significant.

\section{Results}

The TNF- $\alpha$ allelic variants of the polymorphism at position -863 in relation to age, years after menarche, anthropometric characteristics, bone density, bone area and biochemical analysis of the 97 girls are presented in Table 1 . There were $72 \mathrm{C} / \mathrm{C}, 23 \mathrm{C} / \mathrm{A}$ and 2 A/A subjects. The allele frequencies were $86.1 \%$ for $\mathrm{C}$ and $13.9 \%$ for A. The genotype distribution was found to be in Hardy Weinberg equilibrium. To further investigate the effects of the A allele, the population was divided into two groups for further analysis: $-863 \mathrm{C} / \mathrm{C}$ and $-863 \mathrm{C} / \mathrm{A}, \mathrm{A} / \mathrm{A}$. Subjects with the A allele were found to have higher body weight $(P=0.03)$ and lumbar spine BMD $(P=0.02)$, and larger total bone area $(P=0.03)$, femoral neck area $(P<0.05)$, and lumbar spine area $(P=0.01)$ compared with subjects without the A allele. No differences in biochemical variables, including TNF- $\alpha$ plasma levels, between the TNF- $\alpha-863$ genotypes could be detected.

The independent contributors to the variation in bone density were investigated using multiple regression. Physical activity, weight, height, age, and the two groups of TNF- $\alpha$ allelic variants $(-863 \mathrm{C} / \mathrm{C}$ and $-863 \mathrm{C} / \mathrm{A}, \mathrm{A} / \mathrm{A}$ ) were used as explanatory variables. Age was a stronger predictor (for BA and BMD) than age after menarche and was for that reason used in the multivariate analysis. Physical activity was found to be an independent predictor of BMD at all measured sites $(\beta=0.33-0.47, \quad P<0.01)$. Weight was found to be an independent predictor of total BMD $(\beta=0.34, P=<0.01)$ but not of femoral neck BMD or lumbar spine BMD. The TNF- $\alpha$ allelic variants were not independent predictors of BMD at any site $(\beta=-0.10-0.10, P=0.24-0.89)$.

The independent predictors of bone area were investigated using multiple linear regression. This multivariate analysis included body weight, height, age, physical activity, and TNF- $\alpha-863$ alleles (Table 2). Body weight predicted bone area of total body $(\beta=0.54, \quad P<0.01)$, and body height predicted bone area of total body $(\beta=0.43, P<0.01)$ and lumbar spine $(\beta=0.40, P<0.01)$. Physical activity predicted bone area of lumbar spine $(\beta=0.24$,

Table 1 Age, anthropometric data, physical activity, years post menarche, biochemical analysis, bone density and bone area in relation to TNF- $\alpha$ polymorphism at position - 863 in 97 seventeen-year-old girls. Differences were investigated using an independent samples t-test, with Bonferroni's correction for multiple comparisons. Means and standard deviations are presented.

\begin{tabular}{|c|c|c|c|c|}
\hline & \multicolumn{4}{|c|}{ Allelic variants, position -863} \\
\hline & Total $n=97$ & $\begin{array}{c}-863 \mathrm{C} / \mathrm{A}, \mathrm{A} / \mathrm{A} \\
n=25\end{array}$ & $\begin{array}{c}-863 C / C \\
n=72\end{array}$ & $P$-value \\
\hline Age (years) & $16.9 \pm 1.2$ & $17.0 \pm 1.3$ & $16.9 \pm 1.2$ & 0.93 \\
\hline Weight $(\mathrm{kg})$ & $59.9 \pm 6.1$ & $62.0 \pm 5.6$ & $59.0 \pm 6.0$ & 0.03 \\
\hline Height $(\mathrm{cm})$ & $166.5 \pm 5.1$ & $167.3 \pm 5.3$ & $166.3 \pm 5.1$ & 0.40 \\
\hline Physical activity (hours/week) & $4.0 \pm 2.6$ & $4.6 \pm 2.7$ & $3.8 \pm 2.6$ & 0.21 \\
\hline Years after menarche (years) & $4.1 \pm 1.4$ & $4.0 \pm 1.6$ & $4.1 \pm 1.4$ & 0.88 \\
\hline \multicolumn{5}{|l|}{ Bone density $\left(\mathrm{g} / \mathrm{cm}^{2}\right)$} \\
\hline Total body BMD & $1.17 \pm 0.07$ & $1.18 \pm 0.04$ & $1.16 \pm 0.08$ & 0.17 \\
\hline Femoral neck BMD & $1.08 \pm 0.13$ & $1.09 \pm 0.11$ & $1.08 \pm 0.14$ & 0.92 \\
\hline Lumbar spine BMD & $1.22 \pm 0.12$ & $1.26 \pm 0.09$ & $1.21 \pm 0.12$ & 0.02 \\
\hline \multicolumn{5}{|l|}{ Bone area $\left(\mathrm{cm}^{2}\right)$} \\
\hline Total bone area & $2238.5 \pm 166.4$ & $2298.2 \pm 148.8$ & $2217.8 \pm 168.1$ & 0.03 \\
\hline Femoral neck area & $5.1 \pm 0.6$ & $5.3 \pm 0.5$ & $5.1 \pm 0.6$ & $<0.05$ \\
\hline Lumbar spine area & $41.5 \pm 4.2$ & $43.4 \pm 4.2$ & $40.8 \pm 4.0$ & 0.01 \\
\hline \multicolumn{5}{|l|}{ Biochemical analysis (plasma) } \\
\hline Osteocalcin (ng/ml; $n=92)$ & $11.08 \pm 10.15$ & $10.30 \pm 10.98$ & $11.34 \pm 9.93$ & 0.70 \\
\hline Plasma calcium (mmol/l; $n=94)$ & $2.14 \pm 0.08$ & $2.14 \pm 0.06$ & $2.15 \pm 0.08$ & 0.73 \\
\hline Plasma calcium (corrected for albumin; $n=94$ ) & $2.15 \pm 0.06$ & $2.15 \pm 0.06$ & $2.15 \pm 0.07$ & 0.93 \\
\hline $\mathrm{PTH}(\mathrm{pmol} / \mathrm{l})$ & $3.59 \pm 1.77$ & $3.38 \pm 1.17$ & $3.66 \pm 1.94$ & 0.40 \\
\hline Estradiol (pg/ml) & $55.98 \pm 70.68$ & $50.50 \pm 57.04$ & $57.88 \pm 75.10$ & 0.61 \\
\hline TNF- $\alpha(\mathrm{pg} / \mathrm{ml} ; n=84)$ & $4.95 \pm 1.4$ & $5.06 \pm 1.4$ & $4.91 \pm 1.4$ & 0.67 \\
\hline
\end{tabular}


Table 2 Multivariate analysis showing the independent predictors of bone area at measured sites. Age, weight, height, physical activity, and the different TNF- $\alpha$ allelic variants of the polymorphism at position -863 used as explanatory variables. Linear regression coefficient $\beta$ - and $P$-values are presented.

\begin{tabular}{|c|c|c|c|c|c|c|}
\hline \multirow[b]{3}{*}{ Explanatory variables } & \multicolumn{6}{|c|}{ Bone area } \\
\hline & \multicolumn{2}{|c|}{ Femoral neck } & \multicolumn{2}{|c|}{ Lumbar spine } & \multicolumn{2}{|c|}{ Total body } \\
\hline & $\beta$ & $P$ & $\beta$ & $P$ & $\beta$ & $P$ \\
\hline Age (year) & -0.03 & 0.74 & 0.20 & 0.02 & 0.07 & 0.17 \\
\hline Weight (kg) & 0.09 & 0.48 & 0.11 & 0.29 & 0.54 & $<0.01$ \\
\hline Height $(\mathrm{cm})$ & 0.21 & 0.08 & 0.40 & $<0.01$ & 0.43 & $<0.01$ \\
\hline Physical activity (hours/week) & -0.05 & 0.61 & 0.24 & $<0.01$ & 0.11 & 0.02 \\
\hline TNF $\alpha-863$ & 0.17 & 0.10 & 0.18 & 0.03 & 0.04 & 0.45 \\
\hline
\end{tabular}

$P<0.01)$ and total body $(\beta=0.11, P=0.02)$. The TNF- $\alpha-863$ genotypes predicted bone area of the lumbar spine $(\beta=0.18, P=0.03)$ but not of the femoral neck $(\beta=0.17, P=0.1)$ or the total body $(\beta=0.04$, $P=0.45)$.

The same multivariate analysis was performed including the TNF- $\alpha$ plasma levels, and showed that the TNF- $\alpha$ plasma levels were independently correlated to $\mathrm{BA}$ of the lumbar spine $(\beta=0.19 ; P=0.04)$, but not to BA or BMD of any other site measured. Using linear regression, physical activity $(\beta=0.38 ; P=$ $0.001)$, but not estradiol levels, was found to predict the TNF- $\alpha$ plasma levels.

No statistically significant differences in body constitution parameters, biochemical parameters, bone density, or bone area at the measured skeletal sites, were found when comparing the groups defined by the allelic variants at position $-308(P=0.17-0.84)$. There were $75 \mathrm{G} / \mathrm{G}$, and $22 \mathrm{G} / \mathrm{A}$ subjects. The allele frequencies were $88.7 \%$ for $\mathrm{G}$ and $11.3 \%$ for $\mathrm{A}$. The genotype distribution was found to be in Hardy Weinberg equilibrium.

\section{Discussion}

Genetic factors play an important role in the pathogenesis of osteoporosis. Several candidate genes have been studied to examine the effect of allelic variation on bone density. The cytokine TNF- $\alpha$ is an important stimulator of bone resorption $(10,11)$ by enhancing osteoclast development both through a direct effect on osteoclast precursor differentation (17) and indirectly by inducing stromal and osteoblastic cell secretion of essential 'downstream' cytokines such as interleukin-6 and interleukin-11 (27). The stimulatory effect by TNF- $\alpha$ on osteoclast differentation seems to involve both TNF receptor 1 and 2 and, most interestingly, by a pathway independent of RANKL-RANK interaction (17). Recently, a polymorphism in the tumor necrosis factor receptor 2 (TNFR2) was associated with lumbar spine BMD (28). In a study by Ammann et al. (29), transgenic mice expressing high blood levels of a soluble
TNF receptor, neutralizing TNF $\alpha$, was shown to be protected from bone loss caused by estrogen deficiency after ovariectomy. Ammann and co-workers suggested a critical role for TNF- $\alpha$ in the pathogenesis of bone loss induced by estrogen deficiency. Further, estradiol has been shown to directly repress $\mathrm{TNF}-\alpha$ transcription (30).

The TNF- $\alpha$ gene is located in the class III region of the major histocompability complex (MHC) and has been speculated to contribute to MHC associations with autoimmune and infectious diseases (22). Polymorphisms in the promoter region of the TNF- $\alpha$ gene have been identified (19). In a study by Skoog et al. (21), the rare -863 A allele was associated with 31\% lower transcriptional activity in a chloramphenicol acetyltransferase (CAT) reporter gene assay, indicating that the $-863 \mathrm{C} / \mathrm{A}$ polymorphism influences the basal rate of transcription of the TNF- $\alpha$ gene. When analyzing serum concentration in 156 middle-aged men, Skoog and co-workers found significantly lower serum TNF- $\alpha$ levels in carriers of the rare $-863 \mathrm{~A}$ allele, indicating an influence on the expression of the gene in vivo (21).

In our study, the allelic frequencies of the TNF- $\alpha$ -863 polymorphism were similar to a previous study (21). Lumbar spine BMD, total bone area, femoral neck area and lumbar spine area were shown to be significantly higher in carriers of the rare $-863 \mathrm{~A}$ allele. A multivariate analysis was performed using age, weight, height, physical activity, and the different TNF- $\alpha$ allelic variants of the polymorphism at position -863 as explanatory variables in which the TNF- $\alpha-863$ polymorphism was shown to be an independent predictor of lumbar spine bone area. There was no difference in body height between the allelic variants, indicating an influence of the TNF- $\alpha-863$ polymorphism on bone size. Previous studies $(8,31,32)$ have emphasized the importance of bone size as a determinant of bone strength. Further supporting the role of TNF- $\alpha$ in determining bone size, is the observed independent correlation of TNF- $\alpha$ plasma levels to lumbar spine area. However, considering TNF- $\alpha$ as a bone resorption stimulator, our finding that high TNF- $\alpha$ plasma levels 
are correlated to high lumbar spine area are somewhat contradictory. Our data may suggest that the bone turnover rate and the formation rate are greater in subjects with high TNF- $\alpha$ plasma levels. The correlation between the TNF- $\alpha-863$ polymorphism and lumbar spine BMD was lost in the multivariate analysis after being corrected for weight.

In the present study, we could not detect any differences in TNF- $\alpha$ plasma levels between the TNF- $\alpha$ -863 genotypes. The discrepancies between this result and the findings by Skoog et al. (21) could be due to gender differences, since estradiol levels are higher in females than in males and have a direct inhibitory action on TNF- $\alpha$ transcription (30). A limitation of the present study is the relatively small sample size, which may give rise to false associations by chance (type one error), or may fail to detect true differences.

Physical activity was an independent predictor of lumbar spine BA in the present study and has been shown to be correlated to bone area in adolescence (33) and has also been reported to elevate circulating cytokines (34), including TNF- $\alpha$, following exercise. In the present study, physical activity independently predicted both lumbar spine BA and TNF- $\alpha$ plasma levels, suggesting a possible role of TNF- $\alpha$ in the mechanism by which physical activity may increase bone volume.

In conclusion, this study found the TNF- $\alpha-863$ polymorphism and the TNF- $\alpha$ plasma levels to be independent predictors of lumbar spine area in healthy Caucasian adolescent girls.

\section{Acknowledgements}

We thank Anette Contardo and Torsten Sandström for excellent technical assistance. This work was supported by the Swedish Center for Sports Medicine Research (CIF), the Swedish Medical Research Council (no. 7225), and the Swedish Rheumatic Association.

\section{References}

1 Kanis JA, Melton LJ, Christiansen C, Johnston CC \& Khaltaev N. The diagnosis of osteoporosis. Journal of Bone and Mineral Research $199491137-1141$.

2 Boyce WJ \& Vessey MP. Rising incidence of fracture of the proximal femur. Lancet 19851 150-151.

3 Gullberg B, Johnell O \& Kanis JA. World-wide projections for hip fracture. Osteoporosis International 19977 407-413.

4 Slemenda CW, Christian JC, Williams CJ, Norton JA \& Johnston CC Jr. Genetic determinants of bone mass in adult women: a re-evaluation of the twin model and the potential importance of gene interaction on heritability estimates. Journal of Bone and Mineral Research $19916561-567$.

5 Seeman E, Hopper JL, Bach LA, Cooper ME, Parkinson E, McKay J et al. Reduced bone mass in daughters of women with osteoporosis. New England Journal of Medicine 1989320 554-558.
6 Hui SL, Slemenda CW \& Johnston CC Jr. The contribution of bone loss to postmenopausal osteoporosis. Osteoporosis International $1990130-34$.

7 Cummings SR, Black DM, Nevitt MC, Browner W, Lauley J, Ensrud $\mathrm{K}$ et al. Bone density at various sites for prediction of hip fractures. The Study of Osteoporotic Fractures Research Group. Lancet 1993 $34172-75$.

8 Gilsanz V, Loro ML, Roe TF, Sayre J, Gilsanz R \& Schulz EE. Vertebral size in elderly women with osteoporosis. Mechanical implications and relationship to fractures. Journal of Clinical Investigation $1995952332-2337$.

9 Heaney RP, Barger-Lux MJ, Davies KM, Ryan RA, Johnson ML \& Gong G. Bone dimensional change with age: interactions of genetic, hormonal, and body size variables. Osteoporosis International $19977426-431$.

10 Chaudhary LR, Spelsberg TC \& Riggs BL. Production of various cytokines by normal human osteoblast-like cells in response to interleukin-1 beta and tumor necrosis factor-alpha: lack of regulation by 17 beta-estradiol. Endocrinology $1992 \quad 130$ $2528-2534$

11 Lerner UH \& Ohlin A. Tumor necrosis factors alpha and beta can stimulate bone resorption in cultured mouse calvariae by a prostaglandin-independent mechanism. Journal of Bone and Mineral Research $19938147-155$.

12 Pacifici R. Estrogen, cytokines, and pathogenesis of postmenopausal osteoporosis. Journal of Bone and Mineral Research 1996 11 1043-1051.

13 Beutler BA. The role of tumor necrosis factor in health and disease. Journal of Rheumatology $1999 \mathbf{2 6}$ 16-21.

14 Assuma R, Oates T, Cochran D, Amar S \& Graves DT. IL-1 and TNF antagonists inhibit the inflammatory response and bone loss in experimental periodontitis. Journal of Immunology 1998 $160403-409$.

15 Merkel KD, Erdmann JM, McHugh KP, Abu-Amer Y, Ross FP \& Teitelbaum SL. Tumor necrosis factor-alpha mediates orthopedic implant osteolysis. American Journal of Pathology 1999154 203-210.

16 Pfeilschifter J, Chenu C, Bird A, Mundy GR \& Roodman GD. Interleukin-1 and tumor necrosis factor stimulate the formation of human osteoclast-like cells in vitro. Journal of Bone Mineral Research $19894113-118$.

17 Kobayashi K, Takahashi N, Jimi E, Udagawa N, Takami M, Kotake $\mathrm{S}$ et al. Tumor necrosis factor alpha stimulates osteoclast differentiation by a mechanism independent of the ODF/RANKL-RANK interaction. Journal of Experimental Medicine 2000191 275-286.

18 Ota N, Hunt SC, Nakajima T, Suzuki T, Hosoi T, Orimo H et al. Linkage of human tumor necrosis factor-alpha to human osteoporosis by sib pair analysis. Genes and Immunity $20001260-$ 264.

19 Wilson AG, di Giovine FS, Blakemore AI \& Duff GW. Single base polymorphism in the human tumour necrosis factor alpha (TNF alpha) gene detectable by NcoI restriction of PCR product. Human Molecular Genetics 19921353.

20 Wilson AG, Symons JA, McDowell TL, McDevitt HO \& Duff GW. Effects of a polymorphism in the human tumor necrosis factor alpha promoter on transcriptional activation. PNAS $1997 \mathbf{9 4}$ 3195-3199.

21 Skoog T, van't Hooft FM, Kallin B, Joringe S, Boquist S, Nilsson J et al. A common functional polymorphism $(\mathrm{C} \rightarrow \mathrm{A}$ substitution at position -863) in the promoter region of the tumour necrosis factor-alpha (TNF-alpha) gene associated with reduced circulating levels of TNF-alpha. Human Molecular Genetics $1999 \mathbf{8}$ 1443-1449.

22 Wilson AG, di Giovine FS \& Duff GW. Genetics of tumour necrosis factor-alpha in autoimmune, infectious, and neoplastic diseases. Journal of Inflammation $1995 \mathbf{4 5} 1-12$.

23 Bonjour JP, Theintz G, Buchs B, Slosman D \& Rizzoli R. Critical years and stages of puberty for spinal and femoral bone mass accumulation during adolescence. Journal of Clinical Endocrinology and Metabolism 199173 555-563. 
24 Slosman DO, Rizzoli R, Pichard C, Donath A \& Bonjour JP. Longitudinal measurement of regional and whole body bone mass in young healthy adults. Osteoporosis International $1994 \mathbf{4}$ 185-190.

25 Orwoll ES, Oviatt SK \& Biddle JA. Precision of dual-energy x-ray absorptiometry: development of quality control rules and their application in longitudinal studies. Journal of Bone and Mineral Research 19938 693-699.

26 Willis J. Atomic absorption spectrometry. Philips Technical Library $1970525-594$.

27 Romas E \& Martin TJ. Cytokines in the pathogenesis of osteoporosis. Osteoporosis International 1997 7 47-53.

28 Spotila LD, Rodriguez H, Koch M, Adams K, Caminis J, Tenenhouse HS et al. Association of a polymorphism in the TNFR2 gene with low bone mineral density. Journal of Bone and Mineral Research $2000151376-1383$.

29 Ammann P, Rizzoli R, Bonjour JP, Bourrin S, Meyer JM, Vassalli P et al. Transgenic mice expressing soluble tumor necrosis factorreceptor are protected against bone loss caused by estrogen deficiency. Journal of Clinical Investigation 199799 1699-1703.

30 An J, Ribeiro RC, Webb P, Gustafsson JA, Kushner PJ, Baxter JD et al. Estradiol repression of tumor necrosis factor-alpha transcription requires estrogen receptor activation function-2 and is enhanced by coactivators. PNAS $19999615161-15166$.

31 Duan Y, Parfitt A \& Seeman E. Vertebral bone mass, size, and volumetric density in women with spinal fractures. Journal of Bone and Mineral Research 199914 1796-1802.

32 Vega E, Ghiringhelli G, Mautalen C, Rey Valzacchi G, Scaglia H \& Zylberstein $\mathrm{C}$. Bone mineral density and bone size in men with primary osteoporosis and vertebral fractures. Calcified Tissue International $1998 \mathbf{6 2} 465-469$.

33 Nordstrom P, Pettersson U \& Lorentzon R. Type of physical activity, muscle strength, and pubertal stage as determinants of bone mineral density and bone area in adolescent boys. Journal of Bone and Mineral Research 199813 1141-1148.

34 Northoff $\mathrm{H}$, Weinstock C \& Berg A. The cytokine response to strenuous exercise. International Journal of Sports Medicine 1994 $15167-171$

Received 10 September 2001

Accepted 21 December 2001 